\title{
Lived experiences of public elementary school heads in remote schools of Silay City: Self-Concept and behavior
}

\author{
Mellnick, Victoria S.
}

Silay Institute Incorporated, Philippines (victoriamellnick25@gmail.com)

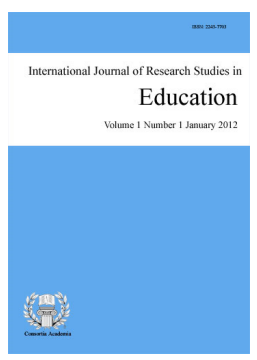

Accepted: 10 June 2021

ISSN: 2243-7703 Online ISSN: 2243-7711

OPEN ACCESS

\section{Abstract}

This study sought to establish the life experiences of School Heads assigned in remote areas of Silay City. The study made use of qualitative design. Data gathering was done through one-on-one interview with the participants. The study made use of a semi structured interview guide that helped establish the information. The result of the study shows that all of the participants were inspired by their family members or an old teacher to become educators themselves. The study equally showed that the School Heads were able to rise above the challenges they faced in school and this have developed a measure of resilience and a sense of improvisation along the way. The School Heads showed a higher sense of care for others, special sense of coping mechanisms and the ability to communicate and collaborate with stake holders and all parties. Finally, all of the participants are in the process of achieving self - realization. Furthermore, it was also noted that all of the participants have future career plans for promotion. Recommendations were made to specific entities to address the needs of the teachers especially those who are assigned in the remote areas.

Keywords: lived experiences, public elementary school heads, self-concept, behavior, remote schools, challenges 


\section{Lived experiences of public elementary school heads in remote schools of Silay City: Self-Concept and behavior}

\section{Introduction}

In its pursuit to provide quality education for every learner, the standard being used by the Department of Education has evolved well enough. Through several key academic initiatives of the department, significant demands on public elementary School Heads' have been made. As the Department of Education continues to face perennial problems like shortage of textbooks, facilities, and classrooms, scarcity of qualified teachers, and others - the role of School Heads continue to evolve and re-shape to meet the demands of their specific locality (Strother, 2014). The same is true for most of the School Heads assigned in far-flung areas in Silay City. Many school heads have to endure the harsh reality of nothingness but sheer determination. In fact, in some remote schools in Silay City, transportation is not available and both teachers and students report to school by walking for hours. Other schools have better access to their schools through the use of a motorcycle. But for some, rough roads and long terrains are only a few of the struggles a teacher must traverse each passing day just to reach their assignment area. School heads need to be there despite bad weather and amidst the danger of being trapped in rebels' places. School heads often have the opportunity to pick their assignment area. Some forego the comforts of urban living and instead choose to accept remote assignments in primitive areas where electricity and transportation are considered a luxury.

Through years of giving up their good life in the city, School Heads assigned in far-flung areas, alongside their teachers and students, had to walk for hours each day, climb mountains and hills, wade across brooks, or cross rivers on a makeshift bridge to go to school and travel back daily, in sweltering heat or pounding rain (Alegado, 2018). With the School Heads in the midst of them, teachers and learners draw their inspiration in religiously reporting to school. While teachers lament handling $\mathrm{K}$ to 12 curriculum after a short one-week training and others are complaining about the lack of instructional materials, the School Heads perpetually make both ends meet. At times, the only option left is to listen to these complaints and act on them within available resources (Weinstein 2014).

The researcher, being a Program Head of the College of Education, Arts and Sciences (CEAS) in a private school in Silay City is interested in knowing how public elementary school heads assigned in remote areas in Silay City manage their time and cope with mounting challenges, both in service and private life. If public elementary School Heads assigned in far-flung areas are packed with challenges every day, how do they turn them into opportunities to fuel their educational leadership? If there is too much pressure for a paradigm shift, from traditional to modern school management, how do school heads keep up with the pace considering all other priorities at hand?

While the government is pushing for an equal opportunity for all to access education, the disparity between urban vis-à-vis rural schooling has a significant gap. The pain of shielding themselves from the sharp edges of scarcity in far-flung schools is what most of the School Heads have to suffer. If pressing issues, challenges, and situations continue to downplay their efforts, all these may take a toll on their physical and psychological well-being. Like the rest of educators, School Heads are parents of their children; some are breadwinners in their own family, and most of all, they too are human beings (Zamora \& Dorado, 2015). This study hopes to shed light on the many issues that confront the teaching profession from the perspective of public elementary school heads assigned in remote areas in Silay City.

\subsection{Research problem}

This study aims to explore the lived experiences of public elementary school heads assigned in the far-flung 
areas of Silay City.

\subsection{Theoretical framework}

The well-being theory by Psychologist Martin Seligman (1942) is mainly characterized by PERMA (positive emotions, engagement, positive relationships, meaning, and achievement or accomplishment) Model. According to Seligman, by focusing on the five elements of the PERMA model, one can flourish in life and discover happiness. Subsequently, PERMA provides the starting point for a greater life. Seligman's theoretical model of happiness (PERMA) helps us understand these elements and what we can do to maximize each element to reach a life full of happiness (Seligman, 2014).

With five core elements of psychological well-being and happiness, Seligman believed that the five elements can help people reach a life of fulfillment, happiness, and meaning. This model is also being applied to institutions to develop programs to help people develop new cognitive and emotional tools. The study is additionally anchored on Maslow's theory on the hierarchy of needs. Maslow's Hierarchy of Needs may be a motivational theory in psychology comprising a five-tier model of human needs, often depicted as hierarchical levels within a pyramid. Needs lower down within the hierarchy must be satisfied before individuals can attend to needs above. From the underside of the hierarchy upwards, the wants are physiological, safety, love, and self - actualization (del Castillo, 2021). This five-stage model will be divided into deficiency needs and growth needs. The primary four levels are often remarked as deficiency needs (D- needs), and also the top-level is understood as growth or being needs (B-needs) (McLeod, 2015).

Deficiency needs arise due to deprivation and are said to motivate people once they are unmet. Also, the motivation to satisfy such needs will become stronger, the longer the duration they're denied. For instance, the longer someone goes without food, the hungrier they'll become. Maslow (1943) initially stated that individuals must satisfy lower- level deficit needs before progressing, to fulfill higher level growth needs. However, he later clarified that satisfaction of a requirement isn't an "all-or-none" phenomenon, admitting that his earlier statements may have given "the error that a requirement must be satisfied $100 \%$ before the subsequent need emerges". In step with Maslow, we've got five categories of needs: physiological, safety, love, esteem, and self-actualization. During this theory, higher needs within the hierarchy begin to emerge when people feel they need sufficiently satisfied the previous need (Hopper, 2019).

When a deficit need has been more or less satisfied it'll get away, and our activities become habitually directed towards meeting the following set of needs that we've got yet to satisfy. These then become our salient needs. However, growth has to still be felt and will even become stronger once the need has been engaged. Growth needs don't stem from a scarcity of something, but rather from a desire to grow as someone. Once these growth needs are reasonably satisfied, one could also be ready to reach the best level called self-actualization (Hopper, 2019).

To better understand what motivates masses, Maslow proposed that human needs can be organized into a hierarchy. This hierarchy ranges from more concrete needs-such as food and water-to more abstract concepts like self-fulfillment. In keeping with Maslow, when a lower need is met, the subsequent need on the hierarchy becomes our focus of attention (Burton,2014). Although Maslow presented his needs during a hierarchy, he also acknowledged that meeting each need isn't an all-or-nothing phenomenon. Consequently, people don't necessarily completely satisfy one need for the subsequent need within the hierarchy to emerge. Maslow suggests that, at any given time, the majority tend to own each of their needs partly met—and that needs lower on the hierarchy are typically those that individuals have made the foremost progress towards (McLeod, 2015).

Additionally, Maslow pointed out that one behavior might meet two or more needs. For example, sharing a meal with someone meets the physiological need for food, but it might also meet the need for belonging. Similarly, working as a paid caregiver would provide someone with income (which allows them to pay for food and shelter), but can also provide them a sense of social connection and fulfillment (Hopper,2019). 


\section{Methodology}

A qualitative research design is employed during the study in keeping with Hammarberg (2016), qualitative research could be a process of naturalistic inquiry that seeks an in-depth understanding of social phenomena within their natural setting. It focuses on the "why" instead of the "what" of social phenomena and relies on the direct experiences of mortals as meaning-making agents in their everyday lives. Instead of logical and statistical procedures, qualitative researchers use multiple systems of inquiry for the study of human phenomena including biography, case study, historical analysis, discourse analysis, ethnography, grounded theory, and phenomenology.

Qualitative researchers are not concerned with the objective truth, but rather the truth of the informants perceive it. This information is necessary to fully understand the behavior of the information. The strength in qualitative research lies in the fact that it is descriptive or exploratory and it stresses the importance of context and the subject's frame of reference. (Barnes,2018).

Polit and Hunger (2013) describe qualitative research as holistic, because it is anxious with people in their immediate environment within the discussion on the character of qualitative research Holloway and Wheeler (2014) state that, "qualitative research relies on the beliefs that knowledge is socially constructed". In using this framework, the researcher accepts that both she and therefore the participants have their values and realities leading to a large number of realities. During this approach, the researcher will primarily employ phenomenological in-depth interviews, introspection, and observations with public school heads assigned to remote areas of Silay City to seek out the character of their experiences, thereby understanding what this particular learning experience was like for them.

\subsection{Locale of the study}

This study was conducted in the Division of Silay City. There are five public elementary schools in remote areas where the study was conducted. These areas were considered as GIDA (geographically isolated and disadvantaged areas. For anonymity, the first school will be called School A, where you need to travel $21 \mathrm{kms}$ from Silay City. Since it was built on top of the hill it is quite difficult to access. The second school, School B is $28 \mathrm{kms}$ from the city and is accessible by a four-wheel-drive vehicle. The problem when you go to this school is that when it is raining the road becomes impassable. The third school, School C, is about $16 \mathrm{kms}$ by four-wheel-drive vehicle but must walk for $2 \mathrm{kms}$ before reaching the school. If you have a motorcycle the road is wide enough for the motorcycle to pass through. School D on the other hand is $30 \mathrm{kms}$ from the city proper. However, you need to cross the river before you can reach their area. Lastly, School E is the farthest school in the Division of Silay. It is around $35 \mathrm{kms}$ by jeepney but students and teachers need to walk $8 \mathrm{kms}$ to access the area. The researcher interviewed the school heads of these five public elementary schools.

Participants. There were 5 school heads assigned to far flung areas in the Division of Silay City who served as participants for this study. Two out of five participants were male and the other three were female.

\subsection{Data gathering procedure}

The researcher followed specific guidelines of STI West Negros University. First step, a letter of request for research was submitted to the Division of Silay City for approval. Second, a letter of request to the informants were sent for their consent for an in=depth interview and lastly a video recorder was made for documentation purposes.

\subsection{Research instrument}

A semi structured interview guide was prepared by the researcher and was reviewed by four qualitative experts. It contained 11 guide questions concerning the lived experiences of the school heads who were assigned in remote areas of Silay City. All interviews, probes and follow-up questions were added as needed to encourage collaboration and clarify responses. Specific questions were added as the interview progressed in response to 
Experiences of public elementary school heads in remote schools of Silay City: Self-Concept and behavior developing themes. All interviews were conducted by the researcher and verbatim transcripts were generated.

\section{Analysis and presentation of data}

\subsection{Thematic Analysis}

Five themes emerged from the Lived Experiences of Public Elementary School Heads in Remote Schools of Silay City: Self Concept and Behavior. Quotes presented throughout the results selection section use code names to protect the identity of the participants.

Inspirational motivation - All of the informants in this study indicated that their reason for joining the education sector is because of their close encounters with previous teachers (relatives or non-relatives) who created an impact on their lives when they were very young. The inspiration they draw from individuals close to their hearts silently motivated them to plant the seed that nurtured their spiritual desire to be in this profession. Respondents 2 and 5 confirmed that when they said, "my former teacher who was so good in teaching; "yes, my teacher convinced me to become a teacher", respectively. According to Vanderbilt University (2019), Intrinsic motivators include fascination with the person or subject, a sense of relevance to life and the world, a sense of accomplishment in mastering it, a sense of calling to it.

Ability to rise above challenges: resilience and improvisation - The ability to rise to every challenge is an inherent flexible character of many Filipinos, so do the school heads. Without a doubt, the informants started to love what they are doing by making use of what is currently available and moving forward out of what they can do with available resources at the moment. Due to this, they learn to improvise things to survive. Respondents 4 and 5 experienced without water supply for nearly 3 years is a moving testimony of their survival in that remote place of assignment. This is confirmed when respondent no. 4 said:

"Being a school head it is difficult to be assigned in a far-flung area where there is no electricity and unavailability of water". She added, tap water for washing is not available.

According to Arellano (2016), "Resilience" is the word that describes the "image of the Filipino people" in times of adversity. Often, traditional and social media depict us as a bunch of people smiling amid the face of adversity. It somehow fosters a national image of a strong nation--the one that bounces back quickly with a joke and a smile as his or her weapon. Seeing this somehow uplifts the spirit and hope that life is normal or shall resume normally soon.

Ability to Collaborate and openly Communicate - School Heads, as educators and leaders, have inherent capabilities to openly communicate with their subordinates, students, and even with the community. However, the informants for this study were uniquely situated in far-flung areas where many people don't know how to read and write. They have to walk an extra mile to be able to reach out. With their ability to effectively communicate, they can establish working collaborations with all stakeholders. These collaborative efforts are mostly translated to assistance, unsolicited help from parents and community, and massive volunteerism.

In her words, Respondent no 4 explained these,"

if you call for a PTA meeting and explain to them the school needs, they are always willing to help. They also send whatever available foods they have like bananas and some root crops if there are school visitors. During fundraising, they are all participating."

According to Little (2018), for the past decade, the 21st Century Community Learning Centers initiative has asked schools to work in partnership with community- and faith-based organizations to support children's learning during the hours after school and the summertime. Consequently, there has been tremendous growth across the nation in intentional efforts to forge meaningful partnerships between schools and afterschool and 
summer programs.

Excessive workload - Teachers in the far-flung areas are doing multitasking because of the multi-grade / integrated setup. On top of this, they are also required to prepare reports. In effect, the School Heads must see to it that these reports must be done and submitted on time.

Respondent 4 said: the volume of paperwork and workload is too high, plus you are always required to submit documents in duplicates especially with the liquidation.

According to Truman (2015), there is a relation between workload and performance. As task demands become extremely high, workload levels may exceed the worker's ability or willingness to commit more skill resources or to exert more effort. The amount of workload a teacher has determined the effectiveness of teaching. Studies carried out in Pennsylvania concluded that output is higher where teachers have a low teaching load and have enough time to prepare their lessons.

A unique sense of care for other - The informant School Heads started lowly as teachers in various schools within the City but most of them were assigned in far-flung areas. When you closely examine their cases, their promotion as School heads simply stretched their abilities, maximized their potentials, and provided them with a greater platform to help others - teachers, students, parents, and the community.

In his words, Respondent no 2 said,

"Yes, I am always looking after their needs. For example, I see that the children were having difficulties carrying their things to and from school so we looked for sponsors so we can provide them with individual lockers similar to that in private schools. We are trying our best to provide them. Sometimes they would complain about walking long distances but I would tell them that's the reality of life, they have to take their share. I educate them that there are a lot of people who are always willing to help. I keep telling them that there is always a solution to every problem."

As per Orlando (2017), a good teacher has his love of learning and inspires students along with his passion for education and therefore the course material. He constantly renews himself as knowledgeable on his quest to produce students with the best quality of education possible. This teacher has no fear of learning new teaching strategies or incorporating new technologies into lessons and always seems to be the one who is willing to share what he's learned with colleagues.

Self-realization - We do things for a reason. Our respondents accepted assignments in far-flung areas for various reasons. One of them is promotion and self-empowerment. According to Wong (2019) promotion is one of the reinforcers of the rewards system to help motivate employees. School heads work very hard and accept assignments in far-flung areas because doing so would help in the realization of their dreams. According to Maslow's Hierarchy of Needs (1943), self-actualization or realization is the ultimate goal of a human being. To achieve this ultimate goal, however, several more basic needs must be met such as the need for food, safety, love, and self-esteem.

Respondent 1: 'Yes, of course, I am aiming for promotion. School Heads have massive work. I foresee myself in 10 years... I will be this..."

Respondent 2:" Yes I have, I am looking at that possibility. Being a school head has not sunk in yet. I have to settle that first and in the future if there is time, I will review and get the supervisory exams.)

Respondent 3: Long-term plans? 'Hmmm someday, I might be too ambitious but I will say this: I am working and striving because someday I want to be a PSDS (Public Schools Division Superintendent)." 


\section{Conclusions}

Based on the significant findings of this study, the following conclusions were drawn. School Heads assigned in far-flung areas of Silay were mostly motivated to become teachers by the same person who inspired them in life like their parents, teachers, and family members. The informants were able to rise above the challenges they encountered by making use of the available resources at that particular time when they assumed the post. Some of them took the initiative to improvise to let the school run despite meager resources. They also showed massive care for their teachers, students, and even the community where the school is situated. The majority of the School Heads showed their care for teachers by making sure that basic needs were attended to. Some of the School Heads walked an extra mile by looking for sponsors to provide for the school needs of some children. The School Heads, being assigned to far-flung areas, were able to defeat boredom with their special coping mechanisms. Some of them diverted their attention to gadgets, some of them reserved their weekends for family and friends. Out of the dire situations of their schools, with less than enough resources to let both ends meet, the School Heads were able to build collaborations within the school and among teachers and students including their immediate communities. As shown previously, their ability to establish linkages indeed helped the school in many ways.

\subsection{Recommendations}

Based on the conclusions and implications, the following recommendations are drawn: The family of school heads assigned in far-flung areas may provide support to continuously uplift the spirit of these educators/leaders. Continue to understand and support them amidst heavy workloads and stresses. The Schools Division Superintendent re-assess the occupational hazards of teachers and school heads who are assigned in remote and far-flung areas and properly compensate for the same. They should create opportunities for School Heads to have ample time with their families and personal lives. The Barangay Officials must extend security assistance to remote schools particularly in areas where school heads and teachers are living. They should also support the basic needs of remote schools like water and electricity.

\section{References}

Alegado, P. J. (2018). The challenges of teacher leadership in the Philippines as experienced and perceived by teachers. International Journal of Education and Research, 6.

Arellano, B. (2018). Retrieved from https://habagatcentral.blogspot.com/2018/08/the-Filipino-spirit-is-resilient-or-is.html

Barnes, J. (2018). The balancing act: The personal and professional challenges of urban teachers. Indiana University Southeast. Urban Educational Journal, 9(1).

Burton, N. (2014). Our hierarchy of needs. A discussion on Psychology today. Psychology Today. Retrieved from https://www.psychologytoday.com/intl/blog/hide-and-seek/201205/our-hierarchy-needs

del Castillo, F. (2021). Self-actualization towards positive well-being: combating despair during the COVID-19 pandemic, Journal of Public Health. https://doi.org/10.1093/pubmed/fdab148

Hammarberg, K., Kirkman, M., \& De Lacey, S. (2016). Human Reproduction, 31(3), 498-501. https://doi.org/10.1093/humrep/dev334

Hopper, E. (2019). Maslow's hierarchy of needs. A discussion on Social Sciences by thoughtco.com. Retrieved from https://www.thoughtco.com/maslows-hierarchy-of-needs-4582571

McLeod, S. A. (2018). Maslow's hierarchy of needs. Simple psychology. Retrieved from https://www.simplypsychology.org/maslow.html

Orlando, R., \& Quejada, A. (2018). Lived experiences of elementary teachers in Samar, Philippines. Journal of academic research, 3(3), 1-13.

Polit, D. F., \& Hungler, B. P. (2013). Essentials of nursing research: Methods, appraisal, and utilization (8th ed). Philadelphia: Wolters. 
Mellnick, V. S.

Seligman, M. E., \& Csikszentmihalyi, M. (2014). Positive psychology: An introduction (pp. 79-298). Springer Netherlands.

Strother, D. (2014). Understanding the lived experiences of secondary teachers instructing in one-to-one computing classrooms. Unpublished dissertation. Drake University, Des Moines, Iowa.

Truman, D. (2019). The influence of work overload time pressure and social influence pressure on auditor's job performance. https://www.researchgate.net/publication/333214308

Weinstein, J. (2014). The problem of rural education in the Philippines. Retrieved from https://joshweinstein.wordpress.com/2010/03/02/the-problem-of-education-in-the-philippines

Wong, J., et al. (2019). The importance of reward system and its impact on employees: Literature review. Retrieved from https://academia.edu/22462105

Zamora, C. M., \& Dorado, R. (2015). Rural-urban education inequality in the Philippines using decomposition analysis. Journal of economics, management \& agricultural development, 1(1). 